Fecha de recepción: septiembre 2008 Fecha de aceptación: octubre 2008 Versión final: diciembre 2008

\section{Consejo Profesional de Relaciones Públicas de la República Argentina. Carta abierta en el $50^{\circ}$ aniversario}

Graciela Fernández Ivern ${ }^{(*)}$

\footnotetext{
${ }^{(*)}$ Licenciada en Relaciones Públicas (UADE). Presidenta del Consejo Profesional de Relaciones Públicas de la República Argentina.
}

Resumen: El presente escrito se realiza en el $50^{\circ}$ del Consejo Profesional de Relaciones Públicas en la Argentina, marco en que se realizó la '1ra Conferencia Internacional de Relaciones Públicas', evento inédito en la Argentina y para la profesión, como un espacio de reflexión, consolidación y proyección hacia el futuro. El objetivo de 'Identidad País: el valor estratégico de las Relaciones Públicas' fue generar un espacio para el análisis y debate del rol de las Relaciones Públicas en los países e instituciones. A la vez, la Presidenta del Consejo Profesional de Relaciones Públicas reflexiona acerca de la misión de la institución y el trabajo mancomunado en comisiones de trabajo que articula las diversas perspectivas de la gestión profesional, y analiza la proyección de las Relaciones Públicas en los próximos años.

Palabras claves: Relaciones Públicas - Reputación Corporativa - Lobbying - Comunicación con el Gobierno - Comunicación de Crisis - Comunicación de Marketing - Responsabilidad Social Empresaria - Comunicación Interna - Comunicación Política - Comunicaciones Integradas - Pymes - opinión pública - imagen corporativa - reputación corporativa - gestión comunicacional - comunicación corporativa - comunicación empresaria - comunicación institucional - Consejo Profesional de Relaciones Públicas de la República Argentina

[Resúmenes en inglés y portugués en la página 82]

\title{
Consejo Profesional de Relaciones Públicas de la República Argentina. Carta abierta en el $50^{\circ}$ aniversario
}

El Consejo Profesional festeja este año su 50 aniversario, cinco décadas en el desarrollo organizado de las Relaciones Públicas en la Argentina.

Desde el nacimiento en el país de la primera asociación en 1958, ejecutivos de empresas, consultores y académicos se esforzaron por el crecimiento y reconocimiento de la profesión. Luego de una serie de aperturas de instituciones y de fusiones entre varias de ellas, el actual Consejo de Relaciones Públicas de la República Argentina es el resultado del trabajo de muchos entusiastas a lo largo de todos estos los años.

En 1989 nació el 'Consejo Profesional de Relaciones Públicas', concluyendo el proceso de integración del sector. Recientemente esta institución ha sido autorizada a funcionar como Consejo Profesional de Relaciones Públicas de la República Argentina. 


\section{El $50^{\circ}$ Aniversario}

Decidimos festejar nuestro 50 aniversario organizando la "1ra Conferencia Internacional de Relaciones Publicas" que se llevo a cabo el 26 de agosto de 2008 en el Sheraton Hotel \& Convention Center. Entendimos que un evento como ese -poco común en la Argentina en nuestra profesión- era útil como espacio de reflexión, consolidación y proyección hacia el futuro.

El título de la conferencia fue 'Identidad País: el valor estratégico de las Relaciones Públicas'. En tiempos de cambio y crecimiento, la Argentina debe plantearse con seriedad, no ya su imagen, sino su identidad como Nación. Para ello, el aporte de los expertos en Relaciones Públicas será de suma importancia.

El objetivo de la conferencia fue generar un espacio para el análisis y el debate sobre el rol que cumplen las Relaciones Públicas en los países e instituciones. Para ello se convocaron a especialistas de ámbitos diversos pero relacionados, para que el conjunto de sus miradas nos ayudara a construir el nuevo paradigma de las Relaciones Públicas.

Se expuso sobre los valores detrás de una identidad del país de cara al próximo Bicentenario, se contribuyó con experiencias puntuales a la reflexión de cómo las empresas globales pueden consolidar la imagen del país. Desde otra óptica, se acercó la visión de cómo gestionar las Relaciones Públicas en el mundo global, sin perder la unidad de voz y contemplando la diversidad cultural de las regiones.

También profesionales de los medios centraron la reflexión en los países, los medios y los foros internacionales, completando el tema a través del análisis profundo del consumo de medios de la región. Y no podríamos hablar hoy de medios y de Relaciones Públicas sin contemplar el advenimiento de Internet y las relaciones on-line, temáticas que tuvieron un intenso tratamiento.

Un aporte sustancial para dilucidar el beneficio público de las Relaciones Públicas fue el de la Presidenta del poderoso Instituto de PR de Gran Bretaña, quien nos acercó asimismo, las conclusiones del 5th World Public Relations Conference \& Festival, de Londres, desarrollado en esa ciudad el pasado mes de junio.

Y por último una mesa centrada en una de las áreas más interesantes de nuestra labor profesional y que más controversias despierta: el lobbying. Destacados miembros del Poder Legislativo Nacional y uno de los más avezados especialistas del país, echaron luz sobre el tema.

Coincidentemente a la 1ra. Conferencia y en festejo del $50^{\circ}$ aniversario llevamos a cabo en la misma semana otros eventos que organizamos anualmente para los jóvenes. Me refiero al Encuentro Anual de Estudiantes y Jóvenes Profesionales de Relaciones Públicas, actividad que lleva ya más de 20 años y que brinda a los jóvenes, durante un día entero, la posibilidad de conectarse con la práctica de la profesión a partir de talleres y exposiciones de especialistas.

También se llevaron a cabo las Olimpíadas de Relaciones Públicas de la que participan los alumnos de las carreras universitarias de Relaciones Públicas de todo el país, resolviendo casos prácticos que se someten a un jurado; experiencias positivas innegables en la vida de un universitario relacionista. Como en todas las profesiones sostenemos que hay quienes la ejercen de pleno derecho y expandiendo sus horizontes con creatividad y principios éticos, y quienes no. Esta es una de las razones por las que a veces, en el espacio público, las Relaciones Públicas son confundidas con otro tipo de acciones. Las dos últimas actividades mencionadas que realizamos año tras año, consolidan nuestra profesión desde las bases de la formación universitaria y son un magnífico aporte al fortalecimiento de los jóvenes profesionales, para que en el futuro la sola mención de Relaciones Públicas no generen ambiguas percepciones. 


\section{El hoy del Consejo Profesional de Relaciones Públicas}

La misión del actual Consejo Profesional de Relaciones Públicas es la de congregar a los profesionales de la actividad, estableciendo estándares éticos, velando por el profesionalismo, promoviendo la investigación y el desarrollo de la actividad en el mercado y defendiendo los intereses de sus miembros. Los pilares de su acción son la mejora constante en la calidad de la comunicación, el respeto de los principios éticos y la transparencia de los vínculos de las organizaciones con sus distintos públicos. En los 50 años transcurridos la profesión ha ido transformándose, adaptándose, tomando mayor preponderancia en las organizaciones y por ende mayor jerarquía, incorporando tecnología y muniéndose de sólidas bases científicas que permiten su desenvolvimiento. Correspondiéndose con lo mismo, en 2008 el Consejo Profesional continúa con su paulatino crecimiento.

Buscamos ser el referente de las Relaciones Públicas en la Argentina y el centro de encuentro de profesionales, ofreciendo un espacio de intercambio y conocimiento que se traduzca en capital intangible. El Consejo cuenta con el gran cuerpo de socios, el Consejo Directivo y 4 Comisiones de trabajo: la de Consultoras que núclea a 30 de las más prestigiosas consultoras nacionales e internacionales; la Corporativa que es formada por ejecutivos de las más importantes empresas del país, la de Educación integrada por las 15 universidades que dictan la carrera de Relaciones Públicas y las de Estudiantes y Jóvenes Profesionales, que como su nombre lo indica reúne a quienes están comenzando a forjar su espacio. Cada una de las Comisiones funciona con su propia agenda y se suscriben a los objetivos generales de la organización.

En cuanto a nuestras relaciones con el resto del mundo sabemos que el intercambio de formación, experiencia y conocimiento de nuevas teorías y conceptos, más allá de nuestras fronteras es vital. Por eso personalmente represento al Consejo Profesional frente a la PRSA -Public Relations Society of America-y al CIPR -Chartered Institute of Public Relations- de Gran Bretaña y, más recientemente, ante la Global Alliance for Public Relations and Communications, una entidad con sede en Londres y Secretaría General en Lugano, Suiza, que agrupa a las asociaciones nacionales de alto prestigio de diferentes países y con la que hemos comenzado a trabajar en proyectos comunes a los países, bajo el paraguas de la ética profesional. Es nuestra intención continuar abriendo caminos de encuentro con otros grupos y asociaciones nacionales e internacionales.

\section{La profesión y su futuro}

La historia y el presente que formaron los especialistas en comunicación durante años anteriores, permitieron una evolución constante de la profesión en el país. El mercado de hoy presenta un notable crecimiento en la cantidad de profesionales y niveles de especialización avanzados, que permitirán continuar el proceso evolutivo de las Relaciones Públicas en la Argentina y en el mundo. Asimismo, la conciencia de las corporaciones de la importancia que tienen la Imagen y la Reputación, el nuevo espectro de medios de comunicación, la intensificación y complejidad de las actividades gubernamentales y las necesidades de ofrecer soluciones concretas a problemas de comunicación, permitirá un crecimiento de la profesión mucho mayor aún al registrado en las últimas décadas.

En este camino, el Consejo Profesional de Relaciones Públicas de la República Argentina, es hoy y será en el futuro, el motor para la integración de las nuevas herramientas, el creador de valor agregado para sus miembros y el fiscalizador del ejercicio profesional, en pos de un marco que brinde a los profesionales del país seguridad, permanencia y el reconocimiento que merecen.

Entendemos que debemos resguardar a nuestros miembros individuales y a la profesión de Rela- 
ciones Públicas en general. Valoramos el rol que nos toca jugar en el sostenimiento de estándares profesionales éticos; en asegurar las "mejores prácticas" y, en definitiva, en ser sostén de una industria que trabaje en el interés y beneficio público.

Deseo y aspiro que todos los que practiquen o deseen practicar esta profesión, puedan integrarse al Consejo Profesional de Relaciones Públicas de la República Argentina para que juntos contribuyamos a que las Relaciones Públicas en la Argentina crezcan y se consoliden aún más.

Lic. Graciela Fernández Ivern Presidente del Consejo Profesional de Relaciones Públicas de la República Argentina

\footnotetext{
Summary: The present article is written in occasion of the $50^{\circ}$ anniversary of the Public Relations Professional Council in Argentina, frame in which The First International Conference of Public Relations was developed. It was an unpublished event in Argentina and for the profession, like a reflection space, consolidation and projection towards the future. The objective of 'Country Identity: the strategic value of Public Relations" was to generate a space for the analysis and debates of the role of Public Relations for countries and institutions. At the same time, the President of the Public Relations Professional Council reflects about the mission of the institution and the joint work in work commissions that articulate the diverse perspective of the professional management, and analyses the projection of the Public Relations in the next years.

Keywords: Public Relations - Corporate Reputation - Lobbying - Public Affairs - Crisis Communication - Marketing Communication - Corporate Social Responsibility - Internal Communication - Political Communication - Integrated Communications - Small and Medium Companies - public opinion - corporate image - communicational management corporate communication - PR Professional Association
}

Resumo: O presente escrito se realiza no 50 do Conselho Profissional de Relações Públicas na Argentina, marco em que se realizou a '1ra Conferência Internacional de Relações Públicas', evento inédito na Argentina e para a profissão, como um espaço de reflexão, consolidação e projeção para o futuro. O objetivo de 'Identidade País: o valor estratégico das Relações Públicas' foi gerar um espaço para a análise e debate do papel das Relações Públicas nos países e instituições. Ao mesmo tempo, a Presidenta do Conselho Profissional de Relações Públicas reflexiona a respeito da missão da instituição e o trabalho mancomunado em comissões de trabalho que articula as diversas perspectivas da gestão profissional, e analisa a projeção das Relações Públicas nos próximos anos.

Palavras chave: Relações Públicas - Reputação Corporativa - Lobbying - Comunicação com o Governo - Comunicação de Crise - Comunicação de Marketing - Responsabilidade Social Empresária - Comunicação Interna - Comunicação Política - Comunicações Integradas - Pymes - opinião pública - imagem corporativa - gestão comunicacional - comunicação corporativa - comunicação empresária - Conselho Profissional de Relações Públicas 